11 Andre FE, Hepburn A, D'Hondt E. Inactivated candidate vaccines for hepatitis A. In: Melnick JL, ed. Progress in medical virology. Vol 37. Basle: Karger, 1990:72-95.

12 Karpinski KF, Hayward S, Tryphonas H. Statistical considerations in the quantitation of serum immunoglobulin levels using the enzyme-linked immunosorbent assay (ELISA). I Immunol Methods 1987;103:189-94.

13 Parry JV, Perry KR, Panday S, Mortimer PP. Diagnosis of hepatitis A and B by testing saliva. $\mathcal{F}$ Med Virol 1989;28:255-60.

14 Ogra PL, Karzon DT, Righthand F, MacGillivray M. Immunoglobulin response in serum and secretions after immunization with live and inactivated polio vaccine and natural infections. N Engl F Med 1968;279: inactivated

15 Wiedermann G, Ambrosch F, Kollaritsch H, Hofmann H, Kunz CH, D'Hondt E, et al. Safety and immunogenicity of an inactivated hepatitis A D'Hondt E, et al. Safety and immunogenicity of an inacivat

16 Stapleton JT, Jansen R, Lemon SM. Neutralising antibody to hepatitis A virus in immune serum globulin and in the sera of human recipients of immune serum globulin. Gastroenterology 1985;89:637-42.
17 Pollock TM, Reid D. Immunoglobulin for the prevention of infectious hepatitis in persons working overseas. Lancet 1969;i:281-3.

18 Hepatitis. Communicable Disease Report 1991;1:2.

19 Tilzey AJ, Banatvala JE. Hepatitis A: changing prevalence and possible vaccines. BMF 1991;302:1552-3.

20 Kani JIA, Nandwani RAK, Gilson RJC, Johnson AM, Maguire HC Tedder RS. Hepatitis A virus infection among homosexual men. BMJ 1991;302:1399.

21 Hepatitis A among drug abusers. MMWR 1988;37:297-301

22 Andre FE. Development of a vaccine against hepatitis A. In: Blaine Hollinger F, Lemon SM, Margolis H, eds. Proceedings of the 1990 international symposium on viral hepatitis and liver disease: contemporary issues and future sympostum on viral hepattits and liver disease: contemp

23 Chin KP, Lok ASF, Wong LSK, Lai C-L, Wu P-C. Current seroepidemiolog of hepatitis A in Hong Kong. I Med Virol 1991;34:191-3.

$24 \mathrm{Lim}$ WL, Yeoh EK. Hepatitis A vaccination. Lancet 1992;339:304

(Accepted 10 March 1992)
Institute of Community Medicine, University of Troms $\varnothing$ N-9001, Troms $\varnothing$, Norway

Biørn Bernersen, research fellow in gastroenterology Roar Johnsen, research fellow in general practice Bjørn Straume, assistant professor in epidemiology

\section{N-9012 University}

Hospital, N-9012 Tromsø,

Norway

Leif Bostad, consultant pathologist

Ann-Inger Sommer, senior researcher in microbiology

Per G Burhol, professor of gastroenterology

Correspondence and requests for reprints to: Dr B Bernersen, Institute of Clinical Medicine, University of Troms $\varnothing$, N-9000 Tromsø, Norway.

BMf 1992;304:1276-9

\title{
Is Helicobacter pylori the cause of dyspepsia?
}

\author{
Bjørn Bernersen, Roar Johnsen, Leif Bostad, Bjørn Straume, Ann-Inger Sommer, Per G Burhol
}

\begin{abstract}
Objective-To determine the association between infection with Helicobacter pylori and dyspepsia.

Design-Cross sectional study of dyspeptic subjects and age and sex matched controls identified by a questionnaire survey of all inhabitants aged 20-69. (Endoscopy, histological examination, and microbiological examinations of biopsies from the gastric mucosa were performed blind.)
\end{abstract}

Setting-Population based survey in Sørreisa, Norway.

Subjects-All 782 dyspeptic subjects (excluding those with a previous history of peptic ulcer, gall stones or kidney stones, and coronary heart disease) and controls were offered an endoscopy, of whom 309 dyspeptic subjects and 310 controls attended.

Main outcome measures-Prevalences of endoscopic and histological diagnoses and of cultures positive for $\boldsymbol{H}$ pylori.

Results-A high prevalence of positive cultures, increasing with age, was found in both dyspeptic subjects (48\%) and non-dyspeptic controls (36\%) $(p=0.004)$. Positive cultures in both dyspeptic subjects and controls were strongly associated with histological gastritis $(\mathbf{7 0} \%, \mathbf{9 5 \%}$ confidence interval 65.5 to $85 \cdot 3 ; 60 \%, 52.7$ to 67.7 , respectively) and peptic ulcer $(92 \%, 61.5$ to $99.8 ; 64.1,9.4$ to 99.2 , respectively). Only $3 \%$ of subjects with a histologically non-inflamed gastric mucosa had this infection (dyspeptic subjects $2 \%, 0.2$ to $7 \cdot 0$; controls $4 \% ; 1.2$ to $8 \cdot 8$ ).

Conclusions-The relation between dyspeptic symptoms and $\boldsymbol{H}$ pylori is dubious; $\boldsymbol{H}$ pylori seems to have a pathogenetic role in gastritis and may be a contributing factor but not a cause of peptic ulcer.

\section{Introduction}

Dyspepsia requires costly management despite lack of knowledge of its causes. The rediscovery by Warren and Marshall ${ }^{1}$ of curved bacilli in the gastric mucosa which were related to gastritis ${ }^{1-3}$ has recharged the discussion about the cause of dyspepsia. A strong association between Helicobacter pylori and gastritis and peptic ulcer disease has been shown in patient populations. ${ }^{148} \mathrm{H}$ pylori has been declared an aetiologic agent of gastritis and even the cause of dyspepsia, though this is disputed..$^{9-12}$ Studies on asymptomatic volunteers have shown high prevalences of $H$ pylori infection, ${ }^{413}{ }^{14}$ of up to $47 \%$ in the age group 60 to $69,{ }^{14}$ but there is little evidence of its prevalence in healthy, normal populations and of the concurrence of $H$ pylori infection and symptoms of dyspepsia. Only one study on the occurrence of $H$ pylori in a general population has been published. ${ }^{15}$ Population based data are mandatory in considering $H$ pylori as a pathogenetic agent in gastritis and peptic ulcer disease and as a possible cause of dyspepsia. ${ }^{616}$

As part of a population based study we examined by endoscopy unselected subjects with dyspepsia and matched non-dyspeptic controls to determine the prevalence of $H$ pylori infection and its relation to endoscopic and histological diagnoses.

\section{Subjects and methods}

From March to May 1987 all inhabitants of the municipality of Sørreisa in northern Norway aged 20 to 69 years, 2027 men and women, received a postal questionnaire with 119 questions about abdominal complaints, health, lifestyle, diet, and social conditions.

All of the subjects answering positively to the first two questions: "Have you ever had abdominal pain of at least two weeks' duration?" and "If yes, was the pain located to the upper abdomen?" or the last question: "Have you ever had heartburn or acid regurgitation almost daily during at least one week?" were considered to have dyspepsia.

After exclusion of 89 dyspeptic subjects with a prior history of peptic ulcer, 15 with gall stones or kidney stones, and 33 with coronary heart disease the remainder were offered an endoscopy free of charge. Corresponding healthy, non-dyspeptic controls matched for sex and age within the same 10 year age group were randomly selected and offered an endoscopy. The controls reported that they had never experienced dyspeptic symptoms and also had never consulted their general practitioner with dyspepsia. Of 2027 subjects invited, $1802(88.9 \%)$ returned the questionnaire. Of 782 subjects invited to endoscopy, 619 (79.2\%) (309 dyspeptic subjects and 310 nondyspeptic controls) had endoscopy, all within one month after returning their questionnaires. A detailed description of the methods has been published elsewhere. ${ }^{17}$ The study was approved by the regional committee for medical research ethics.

\section{ENDOSCOPY}

All endoscopies were performed by $\mathrm{BB}$, who is a trained endoscopist. He was "blinded" in the sense of not knowing whether he was examining a dyspeptic or a non-dyspeptic subject. Endoscopic findings were classified according to criteria described by Savary and Miller (oesophagitis), ${ }^{18}$ Johnsson et al (hiatus hernia), ${ }^{19}$ Myren and Serck-Hanssen (endoscopic gastritis and gastroduodenal reflux), ${ }^{20}$ Nesland and Berstad (erosive 
TABLE I - Prevalence of cultures positive for $H$ pylori from antral mucosa according to age and sex in dyspeptic subjects and non-dyspeptic controls aged 20-69, Sorreisa, Norway, 1987

\begin{tabular}{|c|c|c|c|c|c|c|c|c|c|c|c|c|}
\hline \multirow[b]{3}{*}{ Age group } & \multicolumn{6}{|c|}{ Dyspeptic subjects $(\mathrm{n}=309)$} & \multicolumn{6}{|c|}{ Controls $(n=310)$} \\
\hline & \multicolumn{2}{|c|}{ Men } & \multicolumn{2}{|c|}{ Women } & \multicolumn{2}{|c|}{ Total } & \multicolumn{2}{|c|}{ Men } & \multicolumn{2}{|c|}{ Women } & \multicolumn{2}{|c|}{ Total } \\
\hline & No & $\begin{array}{l}\text { No (\%) } \\
\text { positive }\end{array}$ & No & $\begin{array}{l}\text { No (\%) } \\
\text { positive }\end{array}$ & No & $\begin{array}{l}\text { No (\%) } \\
\text { positive }\end{array}$ & No & $\begin{array}{l}\text { No (\%) } \\
\text { positive }\end{array}$ & No & $\begin{array}{l}\text { No (\%) } \\
\text { positive }\end{array}$ & No & $\begin{array}{l}\text { No (\%) } \\
\text { positive }\end{array}$ \\
\hline $20-29$ & 35 & $11(31)$ & 30 & $9(30)$ & 65 & $20(31)$ & 36 & $8(22)$ & 23 & $3(13)$ & 59 & $11(19)$ \\
\hline $30-39$ & 44 & $24(54)$ & 42 & $24(57)$ & 86 & $48(56)$ & 46 & $17(37)$ & 42 & $16(38)$ & 88 & $33(38)$ \\
\hline $40-49$ & 54 & $24(44)$ & 34 & $20(59)$ & 88 & 44 & 53 & $12(23)$ & 37 & $21(57)$ & 90 & $33(37)$ \\
\hline $50-59$ & 24 & $9(38)$ & 22 & $9(41)$ & 46 & $18(39)$ & 23 & $12(52)$ & 22 & 11 & 45 & $23(51)$ \\
\hline 60-69 & 12 & $9(75)$ & 12 & $8(67)$ & 24 & $17(71)$ & 12 & $4(33)$ & 16 & 8 & 28 & $12(43)$ \\
\hline Total & 169 & $77(46)$ & 140 & $70(50)$ & 309 & $147(48)$ & 170 & $53(31)$ & 140 & $59(42)$ & 310 & $112(36)$ \\
\hline
\end{tabular}

prepyloric changes), ${ }^{21}$ Venables (duodenitis), ${ }^{22}$ and Bernersen et al (peptic ulcer and deformed duodenal bulb). ${ }^{17}$

Biopsy specimens for histological examination were taken from the proximal and distal parts of the duodenum, from both the greater and lesser curvatures of the corpus and antrum of the stomach, and from all lesions as well. Biopsy specimens for culture were also taken from the lesser and from the greater curvature of the antrum about $3 \mathrm{~cm}$ proximal to the pyloric ring. The endoscopes (Olympus gastroscope type GIF-Q 20) and biopsy forceps were cleaned and thereafter disinfected in a commercially available glutaraldehyde solution (Korsolin; Norforma, Rud, Norway) between each endoscopy.

\section{MICROBIOLOGICAL EXAMINATION}

Biopsy specimens for culture were placed in $0.5 \mathrm{ml}$ of glucose/saline solution ( $25 \%$ glucose in $0.9 \%$ saline solution), ground, and cultured on blood agar and on brain-heart infusion agar containing horse $(5 \% \mathrm{v} / \mathrm{v})$ blood within five minutes after endoscopy. The media were incubated in a Gas Pack jar at $37^{\circ} \mathrm{C}$ under microaerobic conditions (Gas generating box Campylobacter bioMerrieux). After three to 10 days any positive cultures, appearing as grey translucent colonies were tested for urease, catalase, and oxidase activities. They were also Gram stained for microscopic examination. The number of positive colonies was evaluated using a semiquantitative scale. $H$ pylori was identified on the basis of positive urease, catalase and oxidase reactions together with a typical microscopic appearance on Gram staining. There were no problems with contamination. The microbiologist had no clinical information on the subjects available.

TABLE II - Prevalence adjusted for age and sex (95\% confidence interval) of cultures positive for $H$ pylori from antral gastric mucosa, according to endoscopic diagnosis

\begin{tabular}{|c|c|c|c|c|}
\hline \multirow[b]{2}{*}{ Endoscopic diagnosis } & \multicolumn{2}{|c|}{ Dyspeptic subjects $(\mathrm{n}=309)$} & \multicolumn{2}{|c|}{ Controls $(n=310)$} \\
\hline & No & No (\%) positive & No & No (\%) positive \\
\hline Normal & 79 & $42(53)(41 \cdot 6$ to $64 \cdot 5)$ & 116 & $41(35)(25 \cdot 8$ to $43 \cdot 4)$ \\
\hline Oesophagitis & 36 & $16(44)(27.9$ to 61.9$)$ & 25 & $6(24)(9 \cdot 4$ to $45 \cdot 1)$ \\
\hline Gastritis & 74 & $42(57)(44 \cdot 7$ to $68 \cdot 2)$ & 63 & $21(33)(22 \cdot 0$ to $46 \cdot 3)$ \\
\hline Biliary reflux & 54 & 31 (57) $(43 \cdot 2$ to $70 \cdot 8)$ & 43 & $15(35)(21 \cdot 0$ to 50.9$)$ \\
\hline Peptic ulcer & 12 & $11(92)(61.5$ to $99 \cdot 8)$ & 3 & $2(64)(9 \cdot 4$ to $99 \cdot 2)$ \\
\hline Erosive prepyloric changes & 119 & $49(41)(32.0$ to $50 \cdot 2)$ & 109 & $41(38)(28 \cdot 3$ to $47 \cdot 0)$ \\
\hline Deformed duodenal bulb & 19 & $13(69)(43 \cdot 5$ to $87 \cdot 4)$ & 10 & $4(39)(12 \cdot 2$ to $73 \cdot 8)$ \\
\hline Duodenitis of duodenal bulb & 61 & 31 (51) (37.7 to $63 \cdot 9)$ & 30 & $8(27)(12.3$ to 45.9$)$ \\
\hline
\end{tabular}

TABLE III - Prevalence adjusted for age and sex (95\% confidence interval) of cultures positive for $H$ pylori from antral gastric mucosa, according to histological diagnosis

\begin{tabular}{|c|c|c|c|c|}
\hline \multirow[b]{2}{*}{ Histological diagnosis } & \multicolumn{2}{|c|}{ Dyspeptic subjects $(\mathrm{n}=309)$} & \multicolumn{2}{|c|}{ Controls $(n=310)$} \\
\hline & No & No (\%) positive & No & No (\%) positive \\
\hline Normal gastric mucosa & 101 & 2 (2) $(0.2$ to 7.0$)$ & 132 & $5(4)(1 \cdot 2$ to $8 \cdot 8)$ \\
\hline Gastritis & 208 & $145(70)(65 \cdot 5$ to $85 \cdot 3)$ & 178 & $107(60)(52 \cdot 7$ to $67 \cdot 7)$ \\
\hline Chronic superficial gastritis & 134 & $102(76)(68.7$ to 83.0$)$ & 117 & $81(69)(61 \cdot 1$ to $71 \cdot 6)$ \\
\hline Chronic atrophic gastritis & 190 & $146(70)(60.8$ to 74.8$)$ & 152 & $95(62)(54.4$ to 70.3$)$ \\
\hline Chronic active gastritis & 78 & $47(61)(48.5$ to $71 \cdot 2)$ & 55 & $35(63)(49 \cdot 3$ to $75 \cdot 9)$ \\
\hline \multirow{2}{*}{$\begin{array}{l}\text { Duodenitis in proximal } \\
\text { duodenum }\end{array}$} & & & & \\
\hline & 180 & $86(48)(40 \cdot 4$ to $55 \cdot 4)$ & 196 & $78(40)(32 \cdot 4$ to $46 \cdot 5)$ \\
\hline
\end{tabular}

\section{HISTOLOGICAL EXAMINATION}

The biopsy specimens, labelled with reference numbers, were formalin fixed and prepared according to standard methods. Thin sections stained with haematoxylin and eosin and periodic acid Schiff and Alcian blue were examined in the department of histopathology at the University Hospital by one experienced pathologist (LB) without any available clinical or microbiological information. Inflammation of the gastric and duodenal mucosa was classified according to Whitehead $e t a l^{324}$ or, when active inflammation was present, according to Owen. ${ }^{25}$

\section{STATISTICAL METHODS}

We analysed our data for both 273 complete matched pairs of subjects and all 619 cases and controls, with similar results. We present the results from the unpaired cases and controls. $\chi^{2}$ and CochranMantel-Haenszel statistics were used to compare the prevalence of $H$ pylori infection overall and in stratified groups. Trends in age were tested by the MantelHaenszel $\chi^{2}$ test. Adjustments for different age and sex distributions in the diagnostic subgroups were made by analysis of covariance with the SPSS-X statistical program. Odds ratios and confidence intervals were calculated according to Fleiss. ${ }^{26}$ Confidence intervals of proportions were calculated from the unadjusted numbers.

\section{Results}

$H$ pylori was cultured from $259(41 \cdot 8 \%)$ of 619 participating subjects (table I). Significantly more positive cultures were obtained from dyspeptic subjects than from non-dyspeptic controls $(48 \% v$ $36 \%, \mathrm{p}=0.004)$. The odds ratios were $1.85(95 \%$ confidence interval $1 \cdot 16$ to 2.95$)$ for men and $1 \cdot 37(0 \cdot 83$ to $2 \cdot 26)$ for women and were only marginally different $(\mathrm{p}=0.053)$. There was a linear increasing trend in prevalence of $H$ pylori with age in both dyspeptic subjects $(p=0.036)$ and controls $(p=0.003)$, which persisted when sex was controlled for.

The prevalence of $H$ pylori in the endoscopic diagnostic subgroups, both with and without peptic ulcer, was compared with that in the group with normal endoscopic findings, controlling for age, sex, and dyspeptic symptoms (table II). Only in the peptic ulcer group was it higher than in the group with a normal endoscopic diagnosis $(p=0.035)$.

Positive culture of $H$ pylori was strongly related to histological findings in the gastric mucosa (table III). The prevalence of $H$ pylori was rare $(3 \%)$ in those subjects with a histologically normal gastric mucosa. When histological gastritis was divided into subtypes according to the degree of inflammation, there were only insignificant differences among positive cultures for the respective subtypes. When histological gastritis of the antrum and corpus were studied separately, however, the prevalence of $H$ pylori infection was significantly higher when the chronic active gastritis 
was located in the mucosa of the antrum than that of the corpus $(70 \% v 43 \%, \mathrm{p}=0.002)$.

\section{Discussion}

The strength of this study is its population base and its design to avoid observer bias. Clinical information was not available to the endoscopist, pathologist, or microbiologist. Dyspepsia has no generally accepted definition, ${ }^{27} 28$ and endoscopic and histological findings may vary with different intensity and duration of the dyspeptic symptoms. ${ }^{29} \mathrm{We}$ chose to restrict the definition to the most commonly accepted symptoms. We found a high prevalence of $H$ pylori in both the dyspeptic subjects and non-dyspeptic controls but a strong association between $H$ pylori and peptic ulcer and histological gastritis. Subjects with a histologically normal mucosa had an almost negligible prevalence of $H$ pylori. The rate of positive cultures of $3 \%$ in this group is within the margin of error for histological findings. It seems reasonable to believe that a histologically normal gastric mucosa is incompatible with $H$ pylori infection.

Other authors have used detection of the organism in stained tissue preparations, ${ }^{16}$ in culture, or both, ${ }^{48-133031}$ and, occasionally, detection of serum antibodies to the organism as criteria for the presence of $H$ pylori infection..$^{32}$ Discrepancies exist between findings based on various diagnostic procedures. ${ }^{143}$ We used only isolation of $H$ pylori as a criterion, and thus we may have detected somewhat lower prevalences than if we had added together all criteria for the presence of $H$ pylori in the gastric mucosa. On the other hand, a rather low occurrence of $3 \%$ in subjects with a histologically normal mucosa indicates a high specificity. This finding agrees with results in a Finnish population based on similar criteria of normality, in which $H$ pylori was present in $5 \%$ of the subjects with a normal antral mucosa. ${ }^{16}$

The prevalences in non-dyspeptic controls in our study were within the same range as in previous studies, ${ }^{41314}$ showing that $H$ pylori infection is quite common even among subjects without dyspepsia, whereas the prevalence of $H$ pylori infection in dyspeptic subjects was lower than previously reported from patient populations. ${ }^{79}$ This may partly reflect our exclusion of subjects with a previously diagnosed peptic ulcer.

Even though there was a higher prevalence of $H$ pylori infection in dyspeptic than non-dyspeptic subjects, $43 \%$ of positive cultures were found among non-dyspeptic controls. Some authors have suggested that this organism plays a major part in non-ulcer dyspepsia. ${ }^{63}$ The high prevalence in non-dyspeptic controls indicates that $H$ pylori infection alone is unlikely to provoke dyspeptic symptoms.

Our study confirms the association between gastritis and $H$ pylori infection. The interesting point is why $H$ pylori is absent in a third of subjects with histological gastritis. One may suggest other properties of the mucosa in these subjects, but a clinical course in which the inflammatory process proceeds after the disappearance of $H$ pylori may also be proposed. ${ }^{35}$

Peptic ulcer was the only endoscopic finding associated with a significantly higher frequency of $H$ pylori infection than endoscopically normal mucosa. Peptic ulcer is associated with gastritis. Antral gastritis is found in a high proportion of patients with duodenal ulcer, ${ }^{36}$ and gastric ulcers are usually found in an area with chronic gastritis. ${ }^{36}{ }^{37}$ As $H$ pylori infection in our study was strongly associated with gastritis our finding of a prevalence of $H$ pylori infection in peptic ulcer as high as $86.5 \%$ may support the theory of a pathogenetic role for this organism in peptic ulcer disease. $H$ pylori infection and gastritis were, however, found in considerable proportion of the population, which heavily weighs against $H$ pylori infection being a sufficient cause of peptic ulcer. The role of $H$ pylori in a causal context may parallel that of gastric acid and pepsin. A strong association was found between $H$ pylori infection and duodenal ulcer. ${ }^{45}$ If deformity of the duodenal bulb is the result of a previous duodenal ulcer a stronger association than we found would be expected between this deformity and $H$ pylori infection. However, this may also reflect the possibility that the $H$ pylori infection resolves with the active ulcer and is not a chronic infection.

Our cross sectional design offers limited possibilities for causal interference, and the causal role of $H$ pylor should be explored in a longitudinal design in which the active $H$ pylori infection, serological findings, gastric mucosal histological findings, and symptoms are surveyed in a cohort.

In conchusion, $H$ pylori infection of the stomach was common both in dyspeptic subjects and in nondyspeptic controls with an increasing prevalence with age. This infection is strongly associated with histological gastritis and peptic ulcer, which may support the theory of a causal role for $H$ pylori in gastritis and at least a role as a pathogenetic factor in peptic ulcer disease. $H$ pylori, like gastric acid and pepsin, may be a necessary but not a sufficient cause of peptic ulcer. The association with symptoms of dyspepsia, on the other hand, is dubious.

1 Warren JR, Marshall B. Unidentified curved bacilli on gastric epithelium in active chronic gastritis. Lancet 1983; i:1273-5.

2 Doenges JL. Spirochetes in the gastric glands of Macacus rhesus and humans without definite history of related disease. Proc Soc Exp Med Biol 1938;38:536-8.

3 Freedberg AS, Barron LE. The presence of spirochetes in human gastric mucosa. American fournal of Digestive Diseases 1940;7:443-5.

4 Langenberg ML, Tytgat GN, Schipper MEI, Rietra PJGM, Zanen HC Campylobacter-like organisms in the stomach of patients and healthy individuals. Lancet 1984;i:1348-9.

5 Goodwin CS, Armstrong JA, Marshall BJ. Campylobacter pyloridis, gastritis, and peptic ulceration. $\mathcal{O}$ Clin Pathol 1986;39:353-65.

6 Dooley CP, Cohen H. The clinical significance of Campylobacter pylori Ann Intern Med 1988;108:70-9.

7 Pettross CW, Appleman MD, Cohen H, Valenzuela JE, Chandrasoma P Laine LA. Prevalence of Campylobacter pylori and association with antral mucosal histology in subjects with and without upper gastrointestinal symptoms. Dig Dis Sci 1988;33:649-53.

8 Rauws EAJ, Langenberg W, Houthoff HJ, Zanen HC, Tytgat GNJ. Campylobacter pyloridis-associated chronic active antral gastritis. Gastroenterolog 1988;94:33-40

9 Marshall BJ, Armstrong JA, McGechie DB, Glancy RJ. Attempt to fulfil Koch's postulates for pyloric campylobacter. Med f Aust 1985;142:436-9.

10 Morris A, Nicholson G. Ingestion of Campylobacter pyloridis causes gastritis and raises fasting gastric $\mathrm{pH}$. Am I Gastroenterol 1987;82:192-9.

11 Peterson WL, Lee EL, Feldman M. Gastric campylobacter-like organisms in healthy humans: correlation with endoscopic appearance and mucosal histology. Gastroenterology 1986;90:1585 (abstract).

12 Bartlett JG. Campylobacter pylori: fact or fancy? Gastroenterology 1988;94: 229-38.

13 Barthel JS, Westblom TU, Havey AD, Gonzales F, Everett ED. Gastritis and Campylobacter pylori in healthy, asymptomatic volunteers. Arch Intern Med 1988;148:1149-5

14 Dooley CP, Cohen H, Fitzgibbons PL, Baner M, Appleman MD, Perez-Perez GI, et al. Prevalence of Helicobacter pylori infection and histologic gastritis in asymptomatic persons. $N$ Engl f Med 1989;321:1562-6.

15 Siurala M, Sipponen P, Kekki M. Campylobacter pylori in a sample of Finnish population: relations to morphology and functions of the gastric mucosa. Gut 1988;29:909-15.

16 Talley NJ, Phillips SF. Non-ulcer dyspepsia: potential causes and pathophysiology. Ann Intern Med 1988;108:865-79.

17 Bernersen B, Johnsen R, Straume B, Burhol PG, Jenssen TG, Stakkevold PA. Towards the "true" prevalence of peptic ulcer. Gut 1990;31:989-92.

18 Savary M, Miller G. Der Oesophagus. Lehrbuch und endoskopischer Atlas. Solothurn: Gassmann, 1977 .

19 Johnsson F, Joelsson B, Gudmunsson K, Greiff L. Symptoms and endoscopic findings in the diagnosis of gastroesophageal reflux disease. Scand $\mathfrak{f}$ Gastroenterol 1987;22:714-8.
Gangs in the diagnosis

20 Myren J, Serck-Hanssen A. The gastroscopic diagnosis of gastritis. Scand $\mathcal{F}$ Gastroenterol 1974;9:457-62.

21 Nesland AA, Berstad A. Erosive prepyloric changes in persons with and without dyspepsia. Scand $\mathcal{F}$ Gastroenterol 1985;20:222-8.

22 Venables CW. Duodenitis. Scand f Gastroenterol 1985;20:(suppl 109):91-7.

23 Whitehead R, Truelove SC, Gear MWL. The histological diagnosis of chronic gastritis in fibreoptic gastroscope biopsy specimens. $\mathcal{F}$ Clin Pathol 1972;25 $1-11$.

24 Whitehead R, Roca M, Meikle DD, Skinner J, Truelove SC. The histological classification of duodenitis in fibreoptic biopsy specimens. Digestion 1975;13 129-36.

25 Owen DA. The diagnosis and significance of gastritis. Pathology. Annual 1979;1:247-1.

26 Fleiss JL. Statistical methods for rates and proportions. New York: Wiley, 1981.

27 Heatley RV, Rathbone BJ. Dyspepsia: a dilemma for doctors? Lancet 1987;ii:779-82. 
28 Colin-Jones DG. Management of dyspepsia: report of a working party. Lancet 1988;i:576-9.

29 Johnsen R, Bernersen B, Straume B, Førde OH, Bostad L, Burhol PG. Prevalences of endoscopic and histological findings in subjects with and without dyspepsia. BMF 1991;302:749-52.

30 Coghlan JG, Gilligan D, Humphries H, McKenna D, Dooley C, Sweeney E, et al. Campylobacter pylori and recurrence of duodenal ulcers - a 12 month follow-up study. Lancet 1987;ii:1109-11.

31 Loffeld RJLF, Potters HVJP, Stobbenringh E, Flendrig JA, Van Spreeuwel JP, Arends JW. Campylobacter associated gastritis in patients with nonulcer dyspepsia: a double blind placebo controlled trial with colloidal bismuth subcitrate. Gut 1989;30:1206-12.

32 Al-Moagel MA, Evans DH, Abdulghani ME, Adam E, Evans DJ, Malaty $\mathrm{HM}$, et al. Prevalence of Helicobacter pylori infection in Saudi Arabia, and com ex Am f Gastroenterol 1990;85:944-7.
33 Jones DM, Lessels AM, Eldridge J. Campylobacter-like organisms on the gastric mucosa: culture, histological, and serological studies. $f$ Clin Pathol 984;37:1002-6.

34 Marshall BJ, McGechie DB, Rogers PA, Glancy RJ. Pyloric campylobacter infection and gastroduodenal disease. Med f Aust 1985;142:439-44.

35 Villako K, Maards H, Tammur R, Keevallik R, Peetsalu M, Sipponen P, et al. Helicobacter pylori infestation and the development and progression of chronic gastritis: results of long-term follow-up examinations of a random sample. Endoscopy 1990;22:114-7.

36 Tatsuta $M$, Iishi $\mathrm{H}$, Okuda $\mathrm{S}$. Location of peptic ulcers in relation to antral and fundal gastritis by chromoendoscopic follow up examinations. Dig Dis $S$ ci 1986;31:7-11.

37 Lawson HH. Effect of duodenal contents on the gastric mucosa under experimental conditions. Lancet 1964;i:469-72.

(Accepted 24 February 1992)

\title{
Investigation of long term problems after obstetric epidural anaesthesia
}

\author{
C MacArthur, M Lewis, E G Knox
}

\section{Abstract \\ Objective-To examine the association between obstetric epidural anaesthesia and subsequent long term problems. \\ Design-Postal questionnaire on health problems after childbirth linked to maternity case note data. \\ Setting-Maternity hospital in Birmingham. \\ Subjects-11 701 women who delivered their most recent child during $1978-85$ and who returned completed questionnaires. \\ Main outcome measures-Frequencies of long} term symptoms after childbirth.

Results -Compared with the 6935 women who did not have epidural anaesthesia the $\mathbf{4 7 6 6}$ women who did more commonly experienced backache (903 $(18.9 \%)$ with epidural $v 731(10.5 \%)$ without epidural), frequent headaches $220(4.6 \%) v 199(2.9 \%)$ ), migraine $(92(1.9 \%)$ v $73(1 \cdot 1 \%))$, neckache (116 $(2.4 \%) v 112(1.6 \%))$, and tingling in hands or fingers $(143(3.0 \%) v 150(2 \cdot 2 \%))$. The results could not be explained by correlated social or obstetric factors. The associations with head, neck, and hand symptoms were found only in women who reported backache. An excess of visual disturbances among women who had epidural anaesthesia $(83(1.7 \%) v$ $91(1 \cdot 3 \%)$ ) was present only in association with migraine, but excess of dizziness or fainting (102 $(2 \cdot 1 \%) v 109(1 \cdot 6 \%)$ ) was independent of other symptoms. 26 women had numbness or tingling in the lower back, buttocks, and leg, of whom 23 had had epidural anaesthesia. Of 34 women with spinal headache, nine (five after accidental dural puncture; four after spinal block) reported long term headaches.

Conclusions-These associations may indicate a causal sequence, although this cannot be proved from this type of study. Randomised trials of epidural anaesthesia are required to determine whether causal relations exist.

\section{Introduction}

Various investigators have reported short term sequelae of epidural anaesthesia, ${ }^{1-5}$ but these studies have generally not examined symptoms after hospital discharge. We previously reported a relation between epidurals and subsequent backache. ${ }^{6}$ We report here an investigation of other long term symptoms after obstetric epidural anaesthesia.

\section{Subjects and methods}

The details of the methods and background to this investigation have been described. ${ }^{67}$ Briefly, the study population consisted of 11701 women who had delivered their most recent child at Birmingham Maternity Hospital between 1978 and 1985. The inquiry was undertaken in January 1987, so the deliveries had occurred at least 13 months previously; the longest follow up period was nine years.

Data were assembled from two sources. The first was the computerised file of maternity case notes, which provided social, obstetric, and anaesthetic data, and the second was postal questionnaires sent to the addresses in the case notes to obtain information on subsequent long term health problems. Twenty five symptoms were specified, and the women were asked whether they had experienced each problem since delivering the index child; if so, they were asked how soon after the birth it had occurred, when it had stopped, whether they had had it before, and whether they had sought medical advice. An open question was also included for reporting any other symptoms.

From this information we defined relevant long term symptoms as those that had started within three months after delivery, had lasted more than six weeks, and had never been experienced before. Recurring symptoms and those inadequately dated were excluded from the main analyses. Unfortunately, we obtained no information on symptom severity and this will be the subject of further investigation.

During the study period 30096 women had delivered at the hospital, but many women had moved from their case note addresses. Using electoral register and Pos Office sources, we were able to estimate that the 11701 who returned completed questionnaires represented a response rate of at least $78 \%$ of those who had received a questionnaire. An examination of the case notes of the non-returners showed that their obstetric and anaesthetic characteristics were similar to those of the respondents.

We used discriminant analysis to establish differences in early events and discriminating circumstances between women who did and did not have symptoms. This procedure takes simultaneous account of a large number of variables and calculates which of them are independent and significant predictors of a particular symptom. It eliminates spurious associations between epidural anaesthesia and subsequent symptoms, which might arise from the fact that this form of anaesthesia is generally associated with less straightforward deliveries (table I) that could also produce subsequent effects. Variables were examined and selected in a stepwise manner, the most significant association being selected first, then the next most significant, and so on. All the associations with epidural anaesthesia reported here were significant after this form of 